\title{
Multi-paradigm model of the region's innovative climate development
}

\author{
Alexandra Egorova ${ }^{1,{ }^{*}}$ and Artyom Uzhegov ${ }^{2}$ \\ ${ }^{1}$ Chelyabinsk State University, 129, Bratyev Kashirinykh, 454001, Chelyabinsk, Russia \\ ${ }^{2}$ Institute of Economics, Chelyabinsk Branch of the Institute of Economics, Ural Branch of the \\ Russian Academy of Sciences, 29, Moskovskaya, 620014, Yekaterinburg, Russia
}

\begin{abstract}
The relevance of the innovative development of regional economies is dictated by both an internal factor (balanced development of territories) and an external factor (the country's competitiveness in the world market). The authors highlight the threats that may arise in different areas of the region's economic activity. The rating system for assessing the innovation climate in the region has been substantiated and developed. The methodology of the author's rating assessment of the innovation climate in the region allows a systematic approach to the qualitative and quantitative characteristics of the state of the innovation climate in the region (good, normal, pre-crisis, crisis). On the basis of the developed assessment system, a multi-paradigm model of the formation of an innovation climate in the region is proposed. The proposed author's model, which reflects the system of factors of the innovation climate in the region, makes it possible to form ways of forming an innovation climate in the context of the selected areas. It seems that the proposed rating system of assessment and the model interconnected with it have applied significance, an integrated approach will allow assessing the level of the innovation climate in the region, and the proposed model will help to develop effective measures to form an innovative climate. The results of the work are the proposed rating system of assessment and a multi-paradigm model interconnected with it. In conclusion, the authors made a number of proposals for the formation of an innovative climate in the region.
\end{abstract}

\section{Introduction}

\subsection{Purpose of the Study}

The aim of this work is to build a multiparadigmal model of the formation of an innovative climate in the region using the example of the Chelyabinsk region.

To achieve this goal, it is necessary to solve a number of basic research problems:

- analyze the existing theoretical approaches to the classification of threats to the innovative development of regions;

- identify threats to the formation of an innovative climate in the region;

\footnotetext{
*Corresponding author: aleksandra_csu@mail.ru
} 
- develop a system for assessing the innovation climate in the region;

- create a model for the formation of an innovative climate in the region.

The object of research is the innovative climate in the region.

The subject of the study is economic relations arising in the process of formation of the innovation climate in the Chelyabinsk region.

The theoretical and methodological basis of the study was the work of domestic and foreign scientists in the field of innovative regional development, innovative activity, problems of the formation of an innovative economy.

The scientific novelty of the study includes the following elements:

1. A study of the approaches of various authors to the innovative development of the region was carried out and on the basis of this, the author's concept of the innovative climate in the region was formulated.

2. A classification of threats to the formation of an innovative climate in the region is proposed.

3. A rating system has been developed to assess the formation of an innovative climate in the region.

4. A multiparadigmal model for the formation of an innovative climate in the region is proposed.

\subsection{Theoretical background}

Studying the issue of ensuring an innovative climate in the region, considerable attention should be paid to the influence of exogenous and endogenous threats, which by their nature impede or make impossible the implementation of state regional policy, which, in turn, leads to the emergence of contradictions between the subjects of the internal and external environment. The key and the root cause of increasing the efficiency of ensuring the innovation climate is the premature clarification and prediction of the possibility of occurrence of phenomena that, directly or indirectly, influence the formation of the innovation climate. The availability of information about the possible emergence of threats will allow us to competently restructure the development policy of the innovation climate and adapt to such a challenge.

The approaches to the classification of threats to the innovative security of the region are quite diverse, such authors as: Novikova, Krasnikov [11], Shekhovtseva [16], Nureev, Simakovsky [13], Petrov, Oganyan [14], Islushchenko, Solovieva [6], Mikhailova [9], Kozhevatova [7], Chub [2], Yakovenko [18], Gorbacheva [5], represent a rather extensive classification of threats to regional innovation security and pay great attention to innovative processes taking place in the regions. It should be noted that the authors highlight the threats of innovation processes taking place in the region, but do not consider innovative development as an interconnected system. So, for example, A. Gorbacheva, in her work notes the following problem areas that can be regarded as threats to innovation security:

- low competitiveness of the human capital of the territories;

- insufficient amount of own investment funds in the regions;

- dysfunctionality of the internal and external innovation market;

- underdevelopment of regional innovation infrastructure.

Domestic scientists also identify threats to innovative development directly in relation to economic security. Among which: Golova [4], Mingaleva, Gershanok [10], Tatarkin, Kuklin [17], Novikova, Krasnikov [12], Krivenko, Elishev [8].

Bagaryakov [1] notes that the main threats in the field of innovation for the constituent entities of the Russian Federation are the following:

- insufficient funding for research and technological development;

- low competitiveness of scientific and technological developments in world markets; 
- low legal security in the field of scientific development.

In our understanding, the innovative climate of the region is a complex of a combination of investment, institutional, and management measures that form an interconnected system aimed at stimulating the development of innovations in the region. It is advisable to consider the approach to the formation of an innovative climate in the region through the following areas:

1. Investment direction.

2. Institutional direction.

3. Research direction.

4. The project direction.

Note that the innovation climate is primarily an interconnected system, and if at least one of the elements of the system is exposed to threats, this will lead to a threat to the entire system as a whole. Thus, it is advisable to highlight the author's vision of the classification of threats to the formation of an innovative climate in the region.

\subsection{Problem Statement}

The formation of an innovative climate in the region raises a number of problems of both scientific and practical content, especially:

- lack of a unique approach to understanding the innovation climate in the region;

- threats that impede the formation of an innovative climate in the region;

- lack of an effective system for assessing innovation processes taking place in the region;

- lack of an integrated system for the formation of an innovative economy.

During the study, the following questions were raised.

1. What threats arise in the formation of an innovative climate in the region?

2. By what parameters can we assess these threats?

3. Is it possible to form a system for assessing the innovation climate in the region?

4. In what areas is it most advisable to form an innovative climate in the region?

\section{Materials and methods}

Studying the issue of ensuring an innovative climate in the region, considerable attention should be paid to the influence of exogenous and endogenous threats, which by their nature impede or make impossible the implementation of state regional policy, which, in turn, leads to the emergence of contradictions between the subjects of the internal and external environment. The key and the root cause of increasing the efficiency of ensuring the innovation climate is the premature clarification and prediction of the possibility of occurrence of phenomena that, directly or indirectly, influence the formation of the innovation climate.

\subsection{Classification of threats to the formation of an innovative climate in the region}

We propose dividing potential threats to the formation of an innovative climate in the region into two groups. The first group will include threats that arise within the region, the second group will include threats that arise in the external environment - it should be noted that the formation of an innovative climate can be influenced by a huge number of factors, we decided to combine the main threats in the areas, we will describe each of them below spheres:

1. Investment sphere - threats arising in the investment sphere are reflected at the general level of the innovation climate. There are no investments, therefore, the innovative potential 
of the region is reduced. As a rule, this sphere is closely connected with all processes aimed at the innovative development of the region; without investments, it is impossible to implement large innovative projects, upgrade the industrial park of an enterprise, introduce innovations, etc.

2. Innovation sphere - separately highlighting the threats to the innovation sphere, we consider them directly as threats that arise in the activities of enterprises that operate in the region.

3. Scientific and technical sphere - the main threats to the scientific and technical sphere is the reduction in the total number of personnel engaged in scientific research. This direction can also include a general decline in youth employed in the scientific and educational sector of the economy.

4. Economic sphere - primarily these threats arise from the external environment. These include the general economic situation of the Russian Federation, the level of inflation, the availability of credit for innovative developments, etc.

5. Legal sphere - threats in the legal sphere are primarily connected with the mechanism of protection and licensing of intellectual property.

6. Institutional area - threats arising in this area are key to attracting investment in the region. An unstable political environment, insecurity of property rights, a shadow economy and corruption are key threats to the formation of an innovative climate in the region.

It should be noted that the division of threats into spheres is rather arbitrary, since each of the spheres directly or indirectly affects another sphere. In Figure 1, we present the threats to the formation of an innovative climate and select in each of the presented areas some indicators for assessing emerging threats.

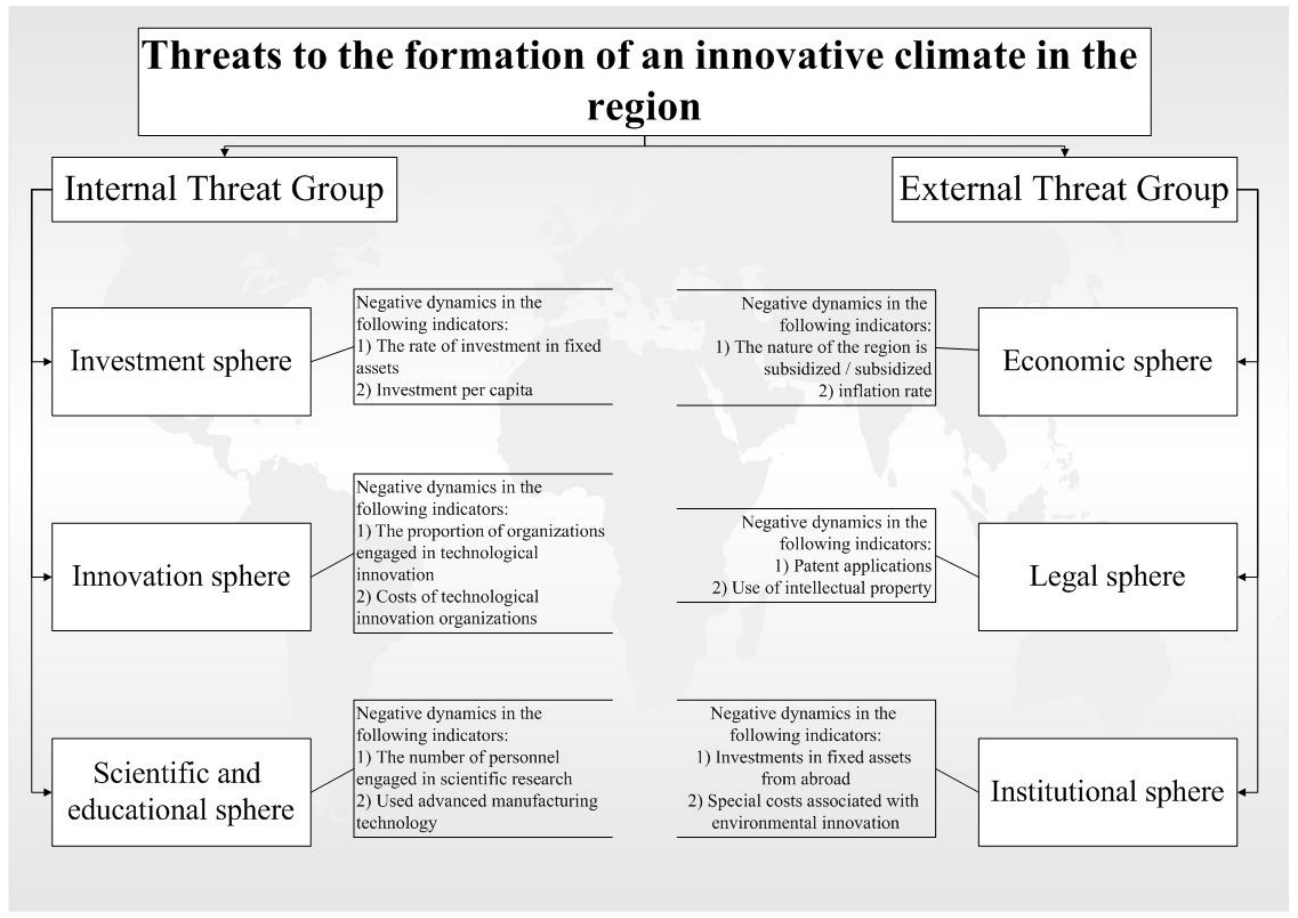

Fig. 1. Threats to the formation of an innovative climate in the region.

So, threats to the formation of an innovative climate in a region are understood to mean factors that make it impossible or significantly impede the process of realizing the innovative interests of a territory, thereby creating a threat to the formation of an innovative climate in 
a region. At the same time, the creation of an appropriate effective assessment system will allow developing an effective mechanism for preventing and minimizing the impact of threats to the formation of an innovative climate that inhibits the development of the region.

Timely assessment of threats to the formation of an innovative climate in the region will contribute to the creation of an organizational and economic mechanism to ensure the formation of an innovative climate in the region and, as a result, the development of an innovative economy in the region. In this regard, it is extremely important to correctly identify and predict the priorities of threats, which allows you to optimally distribute the available resources, forces and assets in the formation of an innovative climate.

It should be noted the instability of the threat system in a market economy. Various threats to the formation of an innovative climate in a region at different time periods can be more or less important.

In our opinion, in today's conditions, the following threats can be considered the main obstacles to the formation of an innovative climate in the region:

1. Financial:

- ineffective tax system for enterprises engaged in innovation;

- instability of the exchange rate;

- the lack of priority of budget expenditures for investment activities of regional development;

- outflow of investments abroad

- lack of an effective credit system for enterprises engaged in innovation;

- a high level of poverty and a large differentiation in wages.

2. Economic:

- a drop in innovation activity, a decrease in production volumes and an increase in the number of unprofitable regional business entities;

- an increase in the need for import of finished products;

- inefficiency of state and regional policies to stimulate innovation;

- decrease in the level and quality of life of the population;

- weakening of the foreign economic position of export-oriented regions, especially industrial ones.

3. Institutional:

- unfavourable institutional environment for attracting investments;

- insufficient funding for research and development;

- lack of conditions for the development of promising youth;

- imperfection of the judicial system;

- lack of infrastructure for generating innovation.

The presence of a significant number of threats requires the implementation of measures to minimize them. So, one of the prerequisites for countering threats is the introduction of measures to regulate the innovative development of the region, which identify and study the causes of the unstable innovative situation in the region, as well as the stages of its development (assessment of the level of innovative climate in the region); development of a plan of economic, financial and other comprehensive transformations in accordance with the provisions of the innovation development strategy of the Russian Federation.

\subsection{Rating system for assessing the formation of an innovative climate in the region}

The basic stage in this process is the implementation of measures related to the determination of the level of innovative climate in the region. This is a multifaceted process that encompasses research on the development of the region's innovative potential. Priority is given to studies affecting economic, innovative and investment processes, since they reflect 
the development of the manufacturing sector of the regional economy and the innovative regional system that provides support for certain standards of innovative infrastructure. Moreover, directly assessing the innovative climate in the region allows us to determine the level of innovative development of the territory.

We propose to carry out a rating assessment of the innovation climate in the region in four stages:

1. Development of a system of indicators of the innovation climate in accordance with the specifics of the region. Each element of the structure is characterized by indicators that reflect the specifics of the development of an innovative regional system. The direct selection of indicators should be carried out taking into account the following points: it is advisable first of all to choose the directions for assessing the innovation climate, then highlight analytical and informational additional indicators. It is necessary to exclude indicators that are difficult to calculate, as well as indicators for which the threshold value cannot be determined [15]; carry out the calculation of indicators, taking into account not only the relationship between them, but also their combined effect on the level of the innovation climate in the region.

2. Calculation of the threshold values of the innovation climate in the region based on the expert method of assessing not only the threshold value, but the "corridor" that defines the precrisis zone of the region's economic development $\mathrm{v}$ the transition from the state of the innovation crisis to the state of innovative development, and vice versa. Determining the real values of indicators and comparing them with threshold values will allow us to assess the true position of the level of innovative climate in the region, since the approximation of indicators to their maximum permissible value indicates a breakdown in intensive innovative development.

3. Analysis of the actual values of the indicator and the limit value, which allows us to determine the level of the innovation climate in the region using one of the indicators, but does not reflect the general development of the territorial entity.

4. Determination of the integral (integrated) scoring of the innovation climate in the region, which reflects the level of development of the regional economy by the aggregate of indicators of the innovation climate in the region.

Summarizing the above, we note that to assess the innovative climate in the region according to the author's methodology, it is required:

- highlight the areas in which we will evaluate the innovative climate in the region;

- assign three indicators to each of the directions;

- expert method to assess the level of threshold values for each of the indicators;

- assign a score from 0 to 1 to each of the indicators. Where 0 is the level of innovative development below the threshold value, and 1 is equal to the threshold value or exceeds it;

- calculate the complex integral estimate.

The rating system of regions is aimed at solving the main tasks of state policy to ensure innovative development, contribute to the formation of an effective system for managing its components, provides for interaction and coordination of activities of public authorities. Among the key tasks in the ranking are:

- development of economic regulation and market tools to ensure the formation of an innovative climate in the region;

- improving the system of state monitoring of the innovative development of the region.

The methodology for rating the level of innovation climate allows:

- assess the level of the innovation climate of individual regions as the final result of innovative development;

- get a general indicator based on a system of indicators for measuring the level of innovative climate in the region;

- carry out a comparison of individual regions according to the level of innovative development; 
- identify the most dangerous from the point of view of innovative development of the territory;

- have an idea of the priority of measures to ensure the formation of an innovative climate in the region.

Thus, at the present stage, the rating can be an objective indicator of the level of innovative climate in the region (Figure 2). Below, we note the author's structure for assessing the innovation climate in the region in 6 directions, in each of the areas we highlight 3 indicators that we propose to use in our methodology.

\section{Rating system for assessing the innovation climate in the region}

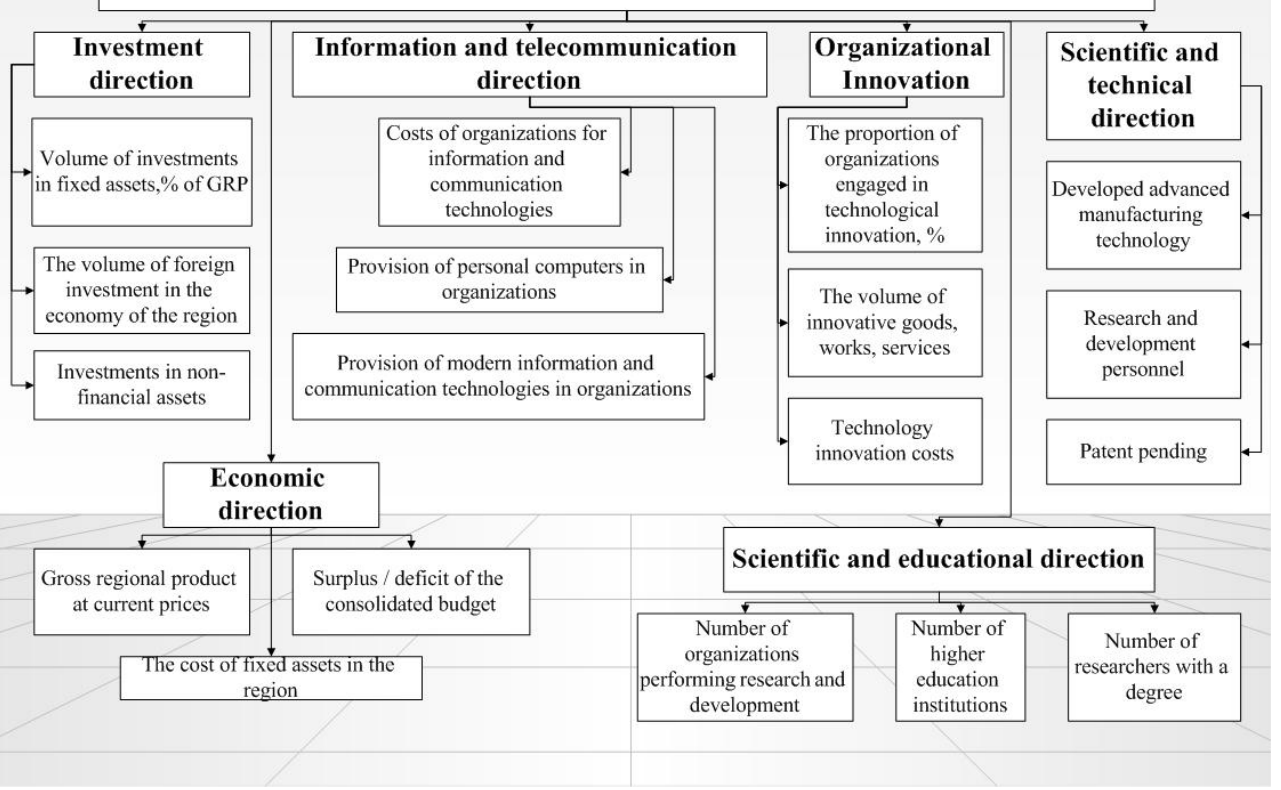

Fig. 2. Rating assessment of the innovation climate in the region by directions.

The calculation of the rating assessment of the innovation climate in the region allows us to determine the quantitative characteristics of the innovation and economic phenomena that occur, to identify the state of the region's innovative development (good, normal, pre-crisis, crisis), the main threats to the region's innovative development in the context of the identified areas. The author's rating scale is presented in Table 1 .

Table 1. Scale for assessing the state of the innovation climate in the region.

\begin{tabular}{|c|c|}
\hline Score Rating & $\begin{array}{c}\text { Qualitative characteristic of the rating score } \\
\text { for innovative development }\end{array}$ \\
\hline $16-18$ & Good \\
\hline $12-16$ & Normal \\
\hline $5-12$ & Pre-crisis \\
\hline $0-5$ & Crisis \\
\hline
\end{tabular}

So, the state of the innovation climate is characterized by a good situation if the regional innovation system is capable of sustainable development and intensive economic growth, ensuring a high level of investment, innovative goods and services, as well as a large number of advanced technologies. The mark in this area should be at least 16 .

The normal situation is characterized by a disruption in the functioning of its individual 
elements, which are a prerequisite for destabilizing the innovative development of the territory; contributes to the deterioration of the situation in the absence of measures to eliminate the causes of negative changes. The mark in this area should be at least 12 .

The main features of the pre-crisis situation are the crisis in the functioning of the main elements of the system (investment, innovation, institutional, economic, scientific and technical). To eliminate this type of threat, it is necessary to implement a set of measures aimed at eliminating threat factors and neutralizing their consequences and at restoring the innovative processes of the region's life. The mark in this area should be at least 5 .

If according to the assessment of innovative development, the region is gaining less than 5 points, then this indicates a crisis in the innovation system of the region. In order to change the negative situation, comprehensive measures should be taken to create an innovative climate in the region.

\section{Results}

After the assessment, it is important to develop activities that would contribute to the integrated formation of an innovative climate in the region. In our understanding, the formation of measures to improve the innovation climate in the region follows from the author's assessment system, in order to consider this issue comprehensively, we used a multiparadigmal model, which implies the possibility of considering reality from different points of view (Figure 3). This model is ideal for our situation, as it allows you to look at the formation of an innovative climate in the region not only from different points of view, but also allows you to adjust the direction of support, from different approaches. So the model makes it possible to use not only the program-targeted approach (project activity), but also the process one (interaction between higher education institutions and business).

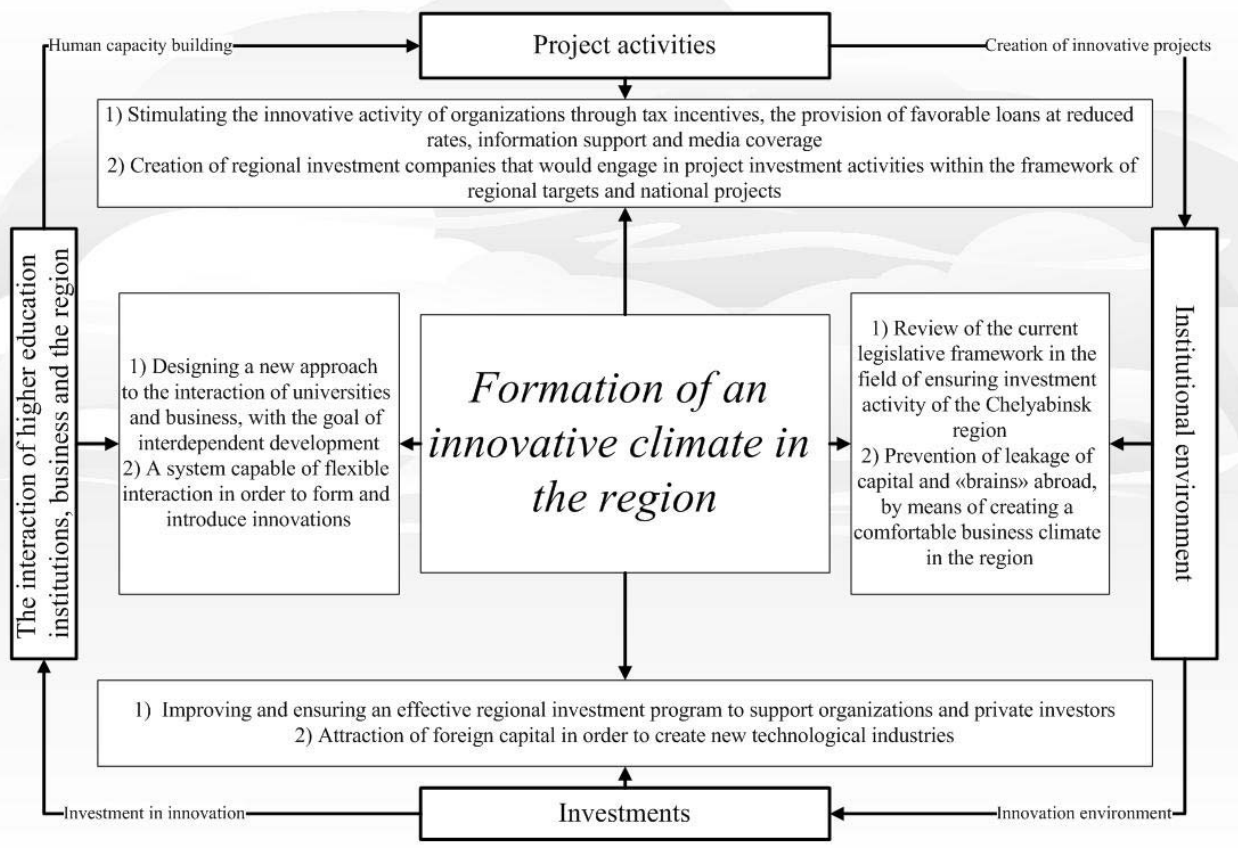

Fig. 3. Multiparadigmal model of the formation of an innovative climate in the region.

In our model, we identified four interrelated areas, we will analyze each in more detail: 
1. By project activity, we mean the work of state regional bodies with the goal of creating and / or helping to create innovative projects. Project activities also include the implementation of regional programs that would encourage private organizations to create innovations - these may be start up support programs, preferential tax programs, etc.

2. By institutional environment, we mean a whole range of measures that directly affects the creation of an innovative climate in the region. Key areas are - the creation of an independent judiciary; revision of the legislative framework in the field of investment activity; fight against corruption; reduction of criminal cases against entrepreneurs; creation of preferential conditions for enterprises introducing innovations; revision of legislation in the field of scientific development; support for young scientists; retention of promising youth in the region, by means of providing various benefits; ensuring the safety of scientific developments.

3. By investment direction, we mean the creation and maintenance of the investment orientation of the region by creating an investment regional program. One of the most important areas, we consider the attraction of foreign capital in order to create new technological industries.

4. We propose to ensure the direction of interaction between higher education institutions, business and the region using the appropriate model [3]. By implementing this approach, we propose to solve the following problems: insufficient funding for research and technological development; low competitiveness of scientific and technological developments in world markets; problems of employment of graduates; negative dynamics of innovative activity of enterprises.

In this regard, in order to create an innovative climate in the Chelyabinsk region, it is necessary to ensure:

1. Improving the investment climate in the region.

2. Improvement and provision of an effective regional investment program to support organizations and private investors wishing to invest in the regional economy.

3. Attraction of foreign capital in order to create new technological industries.

4. Creation of regional investment companies that would be engaged in project investment activities within the target indicators of the region and national projects.

5. Stimulating the innovative activity of organizations through tax incentives, the provision of lucrative loans at reduced rates, information support and media coverage.

6. Effective implementation of regional programs in the area of investment and innovative development.

7. Preventing the flight of capital and "brains" abroad.

\section{Conclusion}

Currently, we are witnessing fundamental changes in all industries, which are associated with the birth of new business models, the transformation of production systems, new interaction among market participants. The formation of the fourth industrial revolution leads to the need to create new economic models focused on effective innovative development.

The conceptual basis of the author's position is that the formation of an innovative climate in the region is a complex process associated with a competent investment policy, the formation of institutional conditions for the implementation of innovations, the transition of interaction between higher educational institutions and business from the standard model of interaction through the "job market" to a complex mutually beneficial cooperation.

Currently, the share of innovative enterprises and projects in the Chelyabinsk region is quite small, and is mainly represented by classical industrial enterprises of metallurgy and mechanical engineering.

In conclusion, it is worth noting that the assessment system we have proposed will help 
to identify weak areas in the development of the innovative climate of the Chelyabinsk region in the shortest possible time, the multi-paradigm model will help develop a set of measures that will effectively respond to emerging threats.

It seems that the proposed rating system of assessment and the model interconnected with it have applied significance, an integrated approach will allow assessing the level of the innovation climate in the region, and the proposed model will help to develop effective measures to form an innovative climate in the Chelyabinsk region.

In future studies, the authors intend to comprehensively develop the concept of the formation of an innovative climate in the region.

\section{Acknowledgement}

The article was prepared in accordance with the Research Plan of the Institute of Economics of the Ural Branch of the Russian Academy of Sciences for 2021.

\section{References}

1. A.V. Bagaryakov, Regional Economy 2 (2012)

2. A.A. Chub, Space of Economics 4-2 (2008)

3. A.A. Egorova, A.O. Uzhegov, 50th International Scientific Conference on Economic and Social Development (2020)

4. I.M. Golova, A.F. Sukhovey, Regional Economy 4 (2017)

5. A. A. Gorbacheva, Space of Economics 4-4 (2008)

6. T.M. Islushchenko, V.K. Solovyova, E.V. Franz, Space of Economics 4-2 (2008)

7. O. V. Kozhevatova, Space of Economics 3-2 (2011)

8. N.V. Krivenko, V.G. Elishev, L.A. Kriventsova, Regional Economy 1 (2019)

9. A.A. Mikhailova, Innovation 1(231) (2018)

10. Z.A. Mingaleva, G.A. Gershanok, Regional Economy 3 (2012)

11. I.V. Novikova, N.I. Krasnikov, Space of Economics 2-3 (2009)

12. I.V. Novikova, N.I. Krasnikov, Regional Economy 4 (2009)

13. R.M. Nureyev, S.A. Simakovsky, Space of Economics 1 (2017)

14. I.V. Petrov, T.M. Oganyan, Space of Economics 1-3 (2012)

15. V.K. Senchagov, Y.M. Maksimov, S.N. Mityakov, O.I. Mityakova, Innovations 5 (2011)

16. L.S. Shekhovtseva, Space of Economics 3 (2006)

17. A.I. Tatarkin, A.A. Kuklin, Regional Economy 2 (2012)

18. Z. M. Yakovenko, Space of Economics 4-2 (2008)

19. D. Pletnev, M. Kazadayev, V. Barkhatov, E3S Web of Conferences 157, 04028 (2020) DOI:10.1051/e3sconf/202015704028

20. D. Pletnev, E. Nikolaeva, Advances in Intelligent Systems and Computing 1116 AISC (2020) DOI:10.1007/978-3-030-37919-3_6 